\title{
Empirical Research on the Chinese Ability of New Vietnamese Female Immigrants in Southern Taiwan
}

\author{
Hsiao-wen Huang \\ Chang Jung Christian University, Taiwan \\ Email: victoria@mail.cjcu.edu.tw \\ Hengli Liao \\ Shiua-Shin Elementary School, Chiayi, Taiwan \\ Email: hhuan004@hotmail.com
}

\begin{abstract}
This research is to investigate the relationship between the demographic data variables of new Vietnamese female immigrants in southern Taiwan and their Chinese language ability. Through statistical analysis, the research shows that the demographic data variables had a significant influence on the "Chinese speaking ability" of new Vietnamese female immigrants in southern Taiwan. This study discovered that (1) new Vietnamese female immigrants working in the service industry are better in Chinese than housewives; (2) new Vietnamese female immigrants with a household income between 40,000-60,000 NT are better in Chinese than those with a household income between 20,000-40,000 NT; (3) new Vietnamese female immigrants that studied Chinese for 6-12 months before they moved to Taiwan are better in Chinese than those that did not; and (4) new Vietnamese female immigrants that studied Chinese for 3 or more semesters after they moved to Taiwan are better in Chinese than those new female immigrants who studied none. Furthermore, new Vietnamese female immigrants that studied Chinese for 2, 3, or more than 3 semesters are better in Chinese than those who only studied Chinese for 1 semester.
\end{abstract}

Index Terms - Chinese ability, new female immigrant, Vietnamese spouse, Taiwan

\section{INTRODUCTION}

\section{A. Research Motivation, Purposes, and Expected Contribution}

In recent years, the number of foreign spouses has increased dramatically in Taiwan. In 2008, of all the foreign spouses who were married to Taiwanese, $58.78 \%$ were Chinese from mainland China, Hong Kong, and Macau with a population of 12,772 , and $41.22 \%$ were from other countries. In 2009 , the non-Chinese foreigners were mostly from south-east Asia with a population as high as 6,009, which represents $67.09 \%$ of the non-Chinese foreign spouses; by observing their country of origin, 4,037 were from Vietnam, 1,109 were from Japan, and 830 were from Indonesia (National Statistical Office 2009). This group of new female immigrants who speak different languages and have different living habits, customs, and cultures are under pressure from the language barrier, differences in eating habits, differences in customs and cultures, and stress from childbirth and educating their children. This pressure is derived from many problems and could have a significant impact on Taiwanese society. In order for these new female immigrants to blend in with Taiwanese society, the priority should be improving their Chinese ability (Hsia 2003). Chang (2008) even pointed out that lack of Chinese ability is the biggest pressure for these new female immigrants. Language is the most important tool for communication and promoting self-interest, and it is also the fastest way to assist new female immigrants to blend in with Taiwanese culture. Only once new female immigrants have Chinese speaking ability can they adopt and develop a personal relationship with the new culture. Therefore, with the increasing numbers of new female immigrants, the improvement of their Chinese ability has become a topic of concern. Nevertheless, the system of compulsory education for all Taiwanese citizens has been implemented in Taiwan for a very long time. With the few exceptions of elders who have not attended school since they were young, and hence have problems reading and writing Chinese, there is almost no illiteracy in Taiwan. This is also a big problem for the future elementary and secondary civil education in Taiwan.

The purpose of the present research is to analyze the relationship between the demographic data variables of new Vietnamese female immigrant and their Chinese ability, and further investigate the influence of these different variables. Currently, the topic centers around the phases of society, system, policy discussion, and adoption on life (Chen and Wang 2005). Therefore this research hopes to contribute to the shortage of resources on new Vietnamese female immigrants learning Chinese language, and further provide suggestions regarding the policies and government aid agencies that are helping new Vietnamese female immigrants who are learning Chinese to increase their learning efficiency and to promote social harmony in Taiwanese society. 


\section{B. Literature Review}

In 2003 the Awakening Foundation started to refer to this group of foreign spouses in Taiwanese as "new female immigrants" (Lee 2006). These foreign spouses are usually younger: 30\% are less than 20 years old, 35\% are between 21-25 years old, and their education level is usually low, with $40 \%$ of them having elementary education and another $40 \%$ with junior high education. In recent years, the percentage of new female immigrants has been gradually increasing, and this group of immigrants has had problems regarding life adjustment, education for children, society adjustment, and cultural shock after they came to Taiwan; among these challenges, the biggest problem is the language barrier and reading Chinese (Hsia 2003). Chen (2008) pointed out that language is the most important tool and medium for understanding and recognizing one's culture; therefore, when new female immigrants came to Taiwan for the first time, Chinese ability became the most important tool to connect them with the world around them. Chinese ability is not only a medium to enhance one's ability to adapt to a new life, it is also a tool and a medium for the weak to live and survive independently; it is as important as the regulations and laws of a country to the living habits and interaction with others. Therefore, new female immigrants could easily be isolated if they have problems with the Chinese ability.

The Ministry of Education agreed in 2002 that the foreign spouses who had acquired "Taiwan district (or alien) residency" or a "Republic of China (Taiwan) passport" could enter a cram or professional school to obtain a formal diploma. Furthermore, they could request that all county and city governments actively establish a new female immigrants' Chinese reading class and promote new female immigrants to enter this class to cultivate their listening, speaking, reading, and writing ability in Chinese. The actual practice measures from the Ministry of Education to promote new female immigrants have been: first, since 2003 all city and county governments have started their own new immigrants Chinese reading classes, with a class size of 20 people for beginner, medium, and upper levels. Secondly, they have also started events such as new female immigrants' teaching classes and observations (Liou 2006). At the moment, the Taiwanese new female immigrants' Chinese language and life education has two types. One type involves accepting new female immigrants in elementary schools or adult education classes. In this form of class, new immigrants often attend along with elders in Taiwan. The other type of class, offered only to new female immigrants, not only educates them in the Chinese language but also provides them with education on different information and techniques useful for living in Taiwan (Chang 2009). Chen (2003) stated that through these classes, new female immigrants could not only learn Chinese but also understand the related regulations; therefore, reading becomes an indispensable ability. Popularizing these Chinese classes will provide immigrants with rich learning resources.

Some researches showed that these new female immigrants have very poor study patterns. Tseng (2004) discovered that over time new female immigrants often have a high absent rate from classes as a result of giving birth, work, or lack of transportation. Yu and Chang (2009) pointed out that in some cases, husbands worried that their new female immigrants spouse will compare themselves with their classmates and therefore forbade them from attending Chinese class. Thus, new female immigrants' education is often interrupted and results in poor learning. Many of these new female immigrants have low learning desires, and as a result, many of these classes are cancelled.

\section{RESEARCh Method AND DataAnALYSis}

\section{A. Research Scope and Subjects}

The female population for this research focused on new female immigrants from Vietnam who are living in areas such as Yunlin County, Chiayi City, Chiayi County, Tainan City, and Tainan County of southern Taiwan. The survey used the purposive sampling method to draw out samples of new female immigrants who were willing to answer the survey. A total of 289 questionnaires were distributed, and 246 were returned. There were 203 valid questionnaires, for a return rate of $70.2 \%$.

\section{B. Data Processing and Analysis}

This research used quantitative methods, including descriptive and inferential statistics. Descriptive statistics utilized analyses such as average, frequency distribution ratio, and standard deviation. The purpose is to understand the demographic data variables of new female immigrants, including age, education, family condition, occupation, household income, length of residency in Taiwan, and time spent studying Chinese before and after they moved to Taiwan. Inferential statistics utilized in this research are the one-way ANOVA and t-test. The purpose of the one-way ANOVA is to investigate the differences of two or more variables; here, it was used to investigate whether or not the demographic data variables of new female immigrants and their Chinese ability differed significantly. When the results of the one-way ANOVA analysis were significant, then the Scheffé method posteriori comparisons were used to understand the differences between the variables.

\section{Research Instruments}

The questionnaire for the quantitative study included two parts: "Demographic data questionnaire" and "Chinese ability scale."

a. Demographic data questionnaire

The purpose of this questionnaire was to understand the new Vietnamese female immigrants' basic demographic data variables including "age," "education level," "family condition," "occupation," "economic condition," "length of 
residency in Taiwan," "time spent studying Chinese before they moved to Taiwan," and "time spent studying Chinese after they moved to Taiwan."

(1) Age: below 20; 21-30; 31-40; 41-50; and 51 and above.

(2) Education level: new female immigrants' education level in Vietnam including elementary school, junior high school, high school, and university/college.

(3) Family condition: lives with husband only; lives with husband and children; lives with husband, children and his family; and lives with husband, children, his family and relatives, and others.

(4) Occupation: housewife; agriculture/forestry/fishing/animal husbandry/engineering; service industry; self-own business; and others.

(5) Household income: under NT 20,000; NT 20,000-40,000; NT 40,000-60,000; NT 60,000-80,000; and NT 80,000 and above (NT: New Taiwanese Dollar).

(6) Length of residency in Taiwan: 1-3 years; 3-5 years; 5-8 years; and 9 years and above.

(7) Time spent studying Chinese before they moved to Taiwan: none; under 3 months; 3-6 months; 6-12 months; and above 1 year.

(8) Time spent studying Chinese after moving to Taiwan: none; 1 semester; 2 semesters; 3 semesters; and above 3 semesters.

b. Chinese ability scale

This scale was designed according to the Test of Chinese as a Foreign Language, TOCFL (2010) made by the Chinese Language Testing Committee commissioned by the Ministry of Education. There are several abilities tested: "Chinese phonetic system application ability," "Chinese listening ability," "Chinese speaking ability," "Chinese literacy," "Chinese characters writing ability," "Chinese reading skill," and "Chinese composition ability," which are for a total of seven questions. Since the participants of this research did not take the TOCFL test, for each question they had to self-evaluate their Chinese ability using a 5 point Likert scale ranked from bad to good: bad $=1$, not so good $=2$, satisfactory $=3$, good $=4$, excellent $=5$; the higher points meant the better the performance. After finishing making this scale, the language education department and Chinese language teaching professors all helped with modifying and adding questions, then it was translated into Vietnamese by a professional translator and grammatically checked by two Vietnamese who had been in Taiwan for a long time to make sure it was fluently and easily understood by the Vietnamese participants. This scale used Cronbach's $\alpha$ coefficient to test the dimensions of each factor to assess the balance and consistency of the scale. As a result, the new female immigrants' Chinese language ability scale reliability of Cronbach's $\alpha$ is 0.92 , which shows that the chart content is consistent and trustworthy. In the validity part, in order to test the scale content and subject relevance and representativeness, the content validity analysis is very important and was determined through the size of the Kaiser-Meyer Olkin (KMO) measure of sampling adequacy. The Chinese ability scale shows a KMO of 0.83 , which represents that the internal efficiency is highly representative.

\section{RESEARCH RESULT}

\section{A. Data Analysis of New Vietnamese Female Immigrant's Demographic Variables}

According to the results, $52.4 \%$ of new Vietnamese female immigrants are between the age of $31-40 ; 51.2 \%$ of them were educated till junior high school; $40.9 \%$ of them lived with their husband and children; $48.3 \%$ of them were in the occupation sector of agriculture/forestry/fishing/animal husbandry/engineering. The average monthly household income was between 20,000-40,000 NT (41.9\%), and 57.6\% of them had been residents of Taiwan for more than 9 years. The possible cause for this result might be that most of the surveys were distributed to Vietnamese moms whose children were between grades 1 to 6 in elementary school. It was found that $51.2 \%$ of the respondents had studied Chinese less than 3 months prior to coming to Taiwan, and $29.6 \%$ of them had studied Chinese for 1 semester after they moved to Taiwan, as shown in Table 1. 
TABLE 1:

DATA ANALYSIS OF NEW VIETNAMESE FEMALE IMMIGRANT'S DEMOGRAPHIC VARIABLES

\begin{tabular}{|c|c|c|c|}
\hline Variables & & Number & Distribution \\
\hline \multirow{3}{*}{ Age } & $21-30$ & 88 & $43.3 \%$ \\
\hline & $31-40$ & 110 & $54.2 \%$ \\
\hline & $41-50$ & 5 & $2.5 \%$ \\
\hline \multirow{4}{*}{ Education level } & elementary school & 24 & $11.8 \%$ \\
\hline & junior high school & 104 & $51.2 \%$ \\
\hline & high school & 65 & $32.0 \%$ \\
\hline & university/college & 10 & $4.9 \%$ \\
\hline \multirow{5}{*}{ Family condition } & lives with husband only & 2 & $1.0 \%$ \\
\hline & lives with husband and children & 83 & $40.9 \%$ \\
\hline & $\begin{array}{l}\text { lives with husband, children and his } \\
\text { family }\end{array}$ & 68 & $33.5 \%$ \\
\hline & $\begin{array}{l}\text { lives with husband, children, his } \\
\text { family and relatives }\end{array}$ & 37 & $18.2 \%$ \\
\hline & others & 13 & $6.4 \%$ \\
\hline \multirow{5}{*}{ Occupation } & housewife & 69 & $34.0 \%$ \\
\hline & $\begin{array}{l}\text { agriculture / forestry / fishing / } \\
\text { animal husbandry / engineering }\end{array}$ & 98 & $48.3 \%$ \\
\hline & service industry & 10 & $4.9 \%$ \\
\hline & Self-own business & 18 & $8.9 \%$ \\
\hline & others & 8 & $3.9 \%$ \\
\hline \multirow{5}{*}{ Household income } & under NT 20,000 & 82 & $40.4 \%$ \\
\hline & NT $20,000-40,000$ & 85 & $41.9 \%$ \\
\hline & NT $40,000-60,000$ & 23 & $11.3 \%$ \\
\hline & NT $60,000-80,000$ & 2 & $1.0 \%$ \\
\hline & NT 80,000 and above & 11 & $5.4 \%$ \\
\hline \multirow{4}{*}{$\begin{array}{l}\text { Length of residency in } \\
\text { Taiwan }\end{array}$} & $1-3$ years & 12 & $5.9 \%$ \\
\hline & $3-5$ years & 20 & $9.9 \%$ \\
\hline & $5-8$ years & 54 & $26.6 \%$ \\
\hline & 9 years and above & 117 & $57.6 \%$ \\
\hline \multirow{5}{*}{$\begin{array}{l}\text { Time spend in studying } \\
\text { Chinese before they } \\
\text { moved to Taiwan }\end{array}$} & None & 27 & $13.3 \%$ \\
\hline & under 3 months & 104 & $51.2 \%$ \\
\hline & 3-6 months & 27 & $13.3 \%$ \\
\hline & 6 months -1 year & 16 & $7.9 \%$ \\
\hline & above 1 year & 29 & $14.3 \%$ \\
\hline \multirow{5}{*}{$\begin{array}{l}\text { Time spend in studying } \\
\text { Chinese after moving to } \\
\text { Taiwan }\end{array}$} & None & 52 & $25.6 \%$ \\
\hline & 1 semester & 60 & $29.6 \%$ \\
\hline & 2 semesters & 23 & $11.3 \%$ \\
\hline & 3 semesters & 20 & $9.9 \%$ \\
\hline & above 3 semesters & 48 & $23.6 \%$ \\
\hline
\end{tabular}

\section{B. Analysis of New Vietnamese Female Immigrants' Chinese Ability}

a. Current situation of new Vietnamese female immigrants' Chinese ability

From table 2, "Chinese listening ability" has the highest score $(\mathrm{M}=3.47)$ follow by "Chinese speaking ability" ( $\mathrm{M}=$ 3.43) and "Chinese phonetic system application ability" $(M=3.10)$. Among these indicators, the average falls around 2.55-3.47, between "satisfactory" and "good." As a whole, new Vietnamese female immigrants in Southern Taiwan have an above average level of Chinese $(\mathrm{M}=3.01)$.

TABLE 2:

ANALYSIS ON NEW VIETNAMESE FEMALE IMMIGRANTS' CHINESE ABILITY

\begin{tabular}{lll}
\hline Items of Chinese ability & Mean & $\begin{array}{l}\text { Standard } \\
\text { Deviation }\end{array}$ \\
\hline Chinese phonetic system application ability & 3.10 & 0.79 \\
Chinese listening ability & 3.47 & 0.77 \\
Chinese speaking ability & 3.43 & 0.77 \\
Chinese literacy & 2.96 & 1.05 \\
Chinese characters writing ability & 2.57 & 1.03 \\
Chinese reading ability & 2.99 & 0.93 \\
Chinese composition ability & 2.55 & 1.07 \\
\hline Total & 3.01 & 0.73 \\
\hline
\end{tabular}

b. Analysis on the relationship between demographic data variables of new Vietnamese female immigrants and their Chinese ability

Through a one-way ANOVA, the findings showed that new Vietnamese female immigrants' "occupation," "household income," "time spent studying Chinese prior to Taiwan," and "time spent studying Chinese after moving to Taiwan" demographic data variables had significant differences in their Chinese ability; moreover, the demographic data variables "age," "educational level," "family condition," and "length of residency in Taiwan" had no significant 
differences.

(1) Difference analysis on new Vietnamese female immigrants' occupations and their Chinese ability.

Table 3 shows that new Vietnamese female immigrants' Chinese ability had significant differences in different job fields $(\mathrm{F}=4.206, \mathrm{p}=.003<.05)$. Through Scheffé method posteriori comparisons, the findings illustrate that new Vietnamese female immigrants that were in the service industry sector had better Chinese ability than that of housewives in southern Taiwan. Therefore, new Vietnamese female immigrants with better Chinese ability had many more job opportunities than those with little Chinese ability, especially in the service industry sector. As new Vietnamese female immigrants improved their Chinese ability, it increased their job opportunities, and they also had a better chance of finding a good job.

TABLE 3:

DIFFERENCE ANALYSIS ON NEW VIETNAMESE FEMALE IMMIGRANTS' OCCUPATIONS AND THEIR CHINESE ABILITY

\begin{tabular}{|c|c|c|c|c|c|}
\hline Variables & Mean & $\begin{array}{l}\text { Standard } \\
\text { Deviation }\end{array}$ & $\mathrm{F}$ value & $P$ value & Scheffé Method \\
\hline Housewife & 20.17 & 4.627 & \multirow{5}{*}{4.206} & \multirow{5}{*}{$0.003 * *$} & \multirow{5}{*}{ service industry $>$ housewife } \\
\hline $\begin{array}{l}\text { Agriculture / forestry / } \\
\text { fishing / animal husbandry } \\
\text { / engineering }\end{array}$ & 20.77 & 5.147 & & & \\
\hline Service industry & 25.50 & 2.991 & & & \\
\hline Own business & 23.94 & 6.530 & & & \\
\hline Others & 20.25 & 2.712 & & & \\
\hline
\end{tabular}

(2) Difference analysis on new Vietnamese female immigrants' household income and their Chinese ability

In table 4 the results show that the new Vietnamese female immigrants' household income had significant differences on their Chinese ability $(\mathrm{F}=3.185$, p- $0.15<0.5)$ in southern Taiwan. Through Scheffé method posteriori comparisons, the research found that new Vietnamese female immigrants who had a household income of more than NT 40,000-60,000 had a higher Chinese ability than those with an income of only NT 20,000-40,000. In other words, families that have a better financial situation also have better Chinese ability. This is perhaps because new Vietnamese female immigrants who are wealthier can spend more time going out, interacting with others and learning Chinese rather than spending their time at work to reduce the financial burden.

TABLE 4:

DIFFERENCES ANALYSIS ON NEW VIETNAMESE FEMALE IMMIGRANTS' HOUSEHOLD INCOME AND THEIR CHINESE ABILITY

\begin{tabular}{|c|c|c|c|c|c|c|}
\hline Variable & Mean & $\begin{array}{l}\text { Standard } \\
\text { Deviation }\end{array}$ & $F$ value & $P$ value & Scheffé Method & \\
\hline Under NT 20,000 & 20.59 & 5.070 & \multirow{5}{*}{3.185} & \multirow{5}{*}{$0.015^{*}$} & \multirow{5}{*}{$\begin{array}{l}\text { NT } 40,000-60,000> \\
20,000-40,000\end{array}$} & \multirow{5}{*}{ NT } \\
\hline NT $20,000-40,000$ & 20.41 & 4.706 & & & & \\
\hline NT 40,000-60,000 & 24.09 & 5.125 & & & & \\
\hline NT $60,000-80,000$ & 25.00 & 5.657 & & & & \\
\hline NT 80,000 and above & 22.55 & 6.517 & & & & \\
\hline
\end{tabular}

(3) Difference analysis on new Vietnamese female immigrants' time spent studying Chinese before they moved to Taiwan and their Chinese ability

The new Vietnamese female immigrants' time spent studying Chinese before they moved to Taiwan and their Chinese ability difference analysis can be seen in table 5. The new Vietnamese female immigrants' time spent studying Chinese before they moved to Taiwan had significant differences on their Chinese ability $(\mathrm{F}=3.910, \mathrm{p}=.004<.05)$. Through the Scheffé method posteriori comparisons, the findings revealed that new Vietnamese female immigrants that studied Chinese for 6-12 months before they moved to Taiwan were much better than those that had never studied. It means that studying Chinese before they moved to Taiwan was very helpful for the new Vietnamese female immigrants of Southern Taiwan.

TABLE 5:

DIFFERENCE ANALYSIS ON NEW VIETNAMESE FEMALE IMMIGRANTS' TIME SPEND IN STUDYING CHINESE BEFORE THEY MOVED TO TAIWAN AND THEIR CHINESE ABILITY

\begin{tabular}{|c|c|c|c|c|c|}
\hline Variable & Mean & $\begin{array}{l}\text { Standard } \\
\text { Deviation }\end{array}$ & $\mathrm{F}$ value & $P$ value & Scheffé Method \\
\hline None & 18.70 & 4.186 & & & \\
\hline Under 3 months & 20.63 & 4.446 & & & \\
\hline 3-6 months & 21.63 & 4.575 & 3.910 & $0.004^{* *}$ & 6 months-1 year $>$ none \\
\hline 6 months-1 year & 23.94 & 5.949 & & & \\
\hline Above 1year & 22.69 & 6.924 & & & \\
\hline
\end{tabular}

(4) Difference analysis on new Vietnamese female immigrants' time spent studying Chinese after they moved to Taiwan and their Chinese ability 
Table 6 shows that the new Vietnamese female immigrants' time spent studying Chinese had a significant impact on their Chinese ability $(\mathrm{F}=4.298, \mathrm{p}=.000<.05)$ in southern Taiwan. Through Scheffé method posteriori comparisons, the findings show that those new Vietnamese female immigrants that studied Chinese for 3 or more semesters had much better Chinese ability than those who had studied none; those who studied Chinese for 2, 3, or more than 3 semesters also had better Chinese ability than those who had only studied for 1 semester. From this, it shows that the new Vietnamese female immigrants who studied more Chinese were better in Chinese ability than those who had only spent a short time studying.

TABLE 6:

DIFFERENCES ANALYSIS ON NEW VIETNAMESE FEMALE IMMIGRANTS' TIME SPEND IN STUDYING CHINESE AFTER THEY MOVED TO TAIWAN AND THEIR CHINESE ABILITY

\begin{tabular}{|c|c|c|c|c|c|}
\hline Variable & Mean & $\begin{array}{l}\text { Standard } \\
\text { Deviation }\end{array}$ & $F$ value & $P$ value & Scheffé Method \\
\hline \multirow{6}{*}{$\begin{array}{l}\text { None } \\
1 \text { semester } \\
2 \text { semesters } \\
3 \text { semesters } \\
\text { Above } 3 \text { semesters }\end{array}$} & 18.65 & 5.967 & \multirow{6}{*}{4.298} & \multirow{6}{*}{$0.000 * * *$} & 3 semesters $>$ none \\
\hline & 19.45 & 3.942 & & & above 3 semesters $>$ none \\
\hline & 21.04 & 3.082 & & & 2 semesters $>1$ semester \\
\hline & 23.85 & 5.040 & & & 3 semesters $>1$ semester \\
\hline & \multirow[t]{2}{*}{24.52} & \multirow[t]{2}{*}{3.820} & & & above 3 semesters $>$ \\
\hline & & & & & 1 semester \\
\hline
\end{tabular}

\section{CONCLUSION}

In this research, most of the new Vietnamese female immigrants of southern Taiwan had been in Taiwan for a substantial period of time, with the majority of them in their 30s, and mostly working in the sector of agriculture/forest/fish/animal husbandry/engineering. Their average household income was between NT 20,000-40,000, and most of them had studied Chinese for less than 3 months before they moved to Taiwan and studied Chinese at the most 1 semester after they moved to Taiwan; this could be because new Vietnamese female immigrants are stuck doing housework or spending time working to assist the family financially; therefore, they could not spend enough time studying Chinese. Moreover, in terms of their Chinese ability, they scored the highest on "Chinese listening ability" followed by "Chinese speaking ability" and "Chinese phonetic system application ability." Their average Chinese ability score is 3.01 (total mean $=3.01$ ), which represents that most of them have above average level of Chinese ability. This research discovered that new Vietnamese female immigrants" "occupation," "household income," "time spent studying Chinese before they moved to Taiwan," and "time spent studying Chinese after they moved to Taiwan" are all factors contributing to their Chinese ability in southern Taiwan. The research results found that: (1) New Vietnamese female immigrants in the service industry sector are better in Chinese than housewives. (2) New Vietnamese female immigrants with a household income between NT 40,000-60,000 are better in Chinese than those who make between NT 20,000-40,000. (3) New Vietnamese female immigrants that studied Chinese for 6-12 months before they moved to Taiwan are better in Chinese than those that did not; and (4) New Vietnamese female immigrants that studied Chinese for 3 or more semesters after they moved to Taiwan are better in Chinese than those new Vietnamese female immigrants who studied none. Furthermore, new Vietnamese female immigrants that studied Chinese for 2, 3, or more than 3 semesters are better in Chinese than those who only studied Chinese for 1 semester.

New Vietnamese female immigrants of southern Taiwan who are better in Chinese ability have more job opportunities than those with little Chinese ability, especially in the service industry sector. As new Vietnamese female immigrants improve their Chinese ability, their job opportunities increase and they can find better jobs; new Vietnamese female immigrants with poor Chinese ability will face bigger challenges in job hunting and would be limited to their family and being full-time housewives. From this finding, having a good level of Chinese ability will help new Vietnamese female immigrants find a job in southern Taiwan. The results of this study are consistent with Dustmann (1994), Chiswick and Miller (1995), Chiswick et al. (1997), and Berman et al. (2000): these analyses from the US, Canada, Australia, Israel, and Germany show that fluency and literacy in the dominant host country language are important components in explaining new immigrants' labor market success. Moreover, the study by Shields and Price (2002) indicates that language is also positively related to the occupational success of some new immigrant groups in the UK. In other words, language proficiency is likely to be a decisive factor in determining employment probabilities. Language may help to acquire information about optimal job search strategies. In this research, new Vietnamese female immigrants who are not sufficiently proficient in the dominant language may have difficulties convincing prospective employers of their qualifications in southern Taiwan. Further, many jobs, for instance in the service industry, require better communication skills. This research also has the same results as the research of Chen (2008). In another way, the Chinese classes the government has started indeed do help new Vietnamese female immigrants with their communication skills, social networking, and expanded job opportunities. By improving their Chinese ability, new Vietnamese female immigrants can expand their living circle beyond their own family in southern Taiwan.

In terms of household income, families that are better off financially could also have an effect on new Vietnamese female immigrants' Chinese ability in southern Taiwan. Possible reasons might be that new Vietnamese female 
immigrants who are better off financially do not need to spend all their time on work, therefore they can have more spare time to go out and interact with others or learn Chinese. This result is similar to that of Chiu (2003) and the Ministry of Education (2007): family support offers motivation for new female immigrants to learn, and recognition from the husband's family is the key factor in supporting new female immigrants to learn Chinese.

New Vietnamese female immigrants that learned Chinese before they moved to Taiwan have better Chinese ability than those with no previous Chinese education. Moreover, new Vietnamese female immigrants that learned Chinese for a longer time than those with little or no Chinese education before they moved to Taiwan, had a higher level of Chinese ability in southern Taiwan; this research result is the same as Chang (2009). In other words, new Vietnamese female immigrants not only learned Chinese through class, but they also built a personal social network and developed personal relationships with the new culture. Therefore, popularizing the Chinese learning classes, it will improve new Vietnamese female immigrants' Chinese proficiency in southern Taiwan.

\section{SUGGestions}

The suggestions for new Vietnamese female immigrants to learn Chinese: no matter whether it is before they move to Taiwan or after they arrive, new Vietnamese female immigrants should plan more time to learn Chinese in order to improve their Chinese proficiency. Improving their Chinese would be beneficial for them in several ways and would also allow them to blend and adjust to a new environment.

Moreover, the suggestions for government agencies: (1) The government should improve their promotion of the policy and encourage new Vietnamese female immigrants to learn Chinese before they moved to Taiwan to reduce the language barrier and learning difficulties. (2) When new Vietnamese female immigrants become residents or citizens of Taiwan, government agencies should grant adequate and stable funding to provide them with more Chinese learning opportunities, and implement and improve their Chinese learning so they can adjust to life in Taiwan which in turn improves their self-esteem, reduces their perception gap as a result of the language barrier, and raises the national competitiveness. As Jordan (2007) recommended, in relation to a study of new immigrants across the U.S., the problem is not the unwillingness of new immigrants to learn the host country language. The real problem is governments do not provide enough classes, so that the U.S. government should be in the business of paying for language instruction for new immigrants. (3) Many new Vietnamese female immigrants have no time to learn Chinese or their learning was interrupted due to reasons such as giving birth to children, responsibility of taking care of the family, financial burden, escaping from the family, or divorce. Whether or not new Vietnamese female immigrants could step outside of their family and learn Chinese is reliant on support from their husbands' families. At the moment, the barriers for new Vietnamese female immigrants to learn Chinese are foreseeable. Therefore, government agencies should care more about this group of new Vietnamese female immigrants and understand the reasons and barriers that prevent them from learning Chinese, and develop relevant policies to actively reduce those factors and increase the efficiency of their Chinese studies.

\section{REFERENCES}

[1] Berman, E., K. Lang \& F. Siniver. (2003). Language-skill complementarity: Returns to immigrant language acquisition. Labour Economics, 10.3, 265-290.

[2] Chang, F. (2009). Taiwan new female immigrants' educational need. Taiwan Education Review, 655, 37-43.

[3] Chang, J. (2008). The research about social need of foreign mates' adapting to Taiwan. The Journal of Chinese Public Administration, 5, 165-174.

[4] Chen, Y. Z. (2008). A study of the cultural identity, social adaptation and social network of new immigrants in Taiwan. Journal of State and Society, 4, 43-100.

[5] Chen, S. \& H. Wang. (2005). "Heaven's Wedding Gown?" -Study on the practices of dressing and appearance consumption by Vietnamese brides in Taiwan. Taiwanese Sociological Association Annual Meeting and Conference. http://www.ntpu.edu.tw/ tsa/schedule/schedule.htm (accessed 10/10/2010).

[6] Chen, Y. H. (2003). From the diversity-culture perspective to expound the practice of foreign spouses' education. Adult Education Bimonthly, 75, 20-30.

[7] Chiswick, B. R. \& P. W. Miller. (1995). The endogeneity between language and earnings: International analyses. Journal of Labor Economics, 13, 246-288.

[8] Chiswick, B. R., Y. Cohen \& T. Zach. (1997). The labor market status of immigrants: effects of the unemployment rate at arrival and duration of residence. Industrial and Labor Relations Review, 50, 289-303.

[9] Chiu, F. (2003). An explorer on Southeast Asian foreign brides' family problem and assistance needs. Community Development Quarterly, 101, 176-181.

[10] Dustmann, C. (1994). Speaking fluency, writing fluency and earnings of immigrants. Journal of Population Economics, 7 , 133-156.

[11] Hsia, H. (2003). The localization of praxis-oriented research: the Case of "Foreign Brides Literacy Programs". Taiwan: A Radical Quarterly in Social Studies, 49, 1-47.

[12] Jordan, M. (2007). Huddled classes yearning to learn free; demand for no-cost lessons could explode if congress requires English proficiency. Wall Street Journal, b1. http://www.wsjclassroom.com/cre/files/feb09/09feb_additional_huddled_classes.pdf (accessed 10/11/2010).

[13] Lee, Y. (2006). Towards "the Other" and "Empowerment": the discussion on new female immigrants' learning and teaching. 
Journal of Education Research, 141, 25-36.

[14] Liou, B. (2006). A study on the immigrant brides' literacy classes propelled by Chiayi city education bureau. (Unpublished thesis). National Chung Cheng University, Taiwan.

[15] Ministry of Education. (2007). Zero distance through education: The documentary publication of "Taiwanese brides holding hand to study." http://english.moe.gov.tw/public/Attachment/7121715593771.doc (accessed 28/10/2010).

[16] National Statistical Office (2009). 2009 the $3^{\text {rd }}$ week Statistical Bulletin of Internal affair-2009 the number of foreign spouses (including mainland China, Hong Kong, and Macau) married to Taiwanese. http://www.moi.gov.tw/stat/news_content.aspx?sn=1990 (accessed 18/09/2010).

[17] Shields, M. A. \& S. W. Price. (2002). The English language fluency and occupational success of ethnic minority immigrant men living in English metropolitan areas. Journal of Population Economics, 15, 137-160.

[18] Test of Chinese as a Foreign Language (TOCFL) (2010). Steering Committee for the Test of Proficiency-Huayu. http://www.sc-top.org.tw/chinese/history.php (accessed 15/09/2010).

[19] Tseng, S. (2004). A discussion on foreign spouses' education curriculum planning. Community Development Quarterly, 105, 227-235.

[20] Yu, P. \& Y. Chang. (2009). The Study on Chinese Learning of New Immigrants. Journal of National United University, 6.1, 207-222.

Hsiao-wen Huang is an assistant professor in Department of Information Management and Center of Language Education at Chang Jung Christian University of Tainan, Taiwan. She received her Ed. D. degree in Adult and Higher Education from University of South Dakota in USA. Her areas of specialization are: Adult and Continuing Education, Higher Education and TCSOL (Teaching Chinese to Speakers of Other Language).

Hengli Liao is a primary school teacher in the Municipal Shiuan Shin Elementary School, Chiayi, Taiwan. 